\title{
Female reproductive tract infections: understandings and care seeking behaviour among women of reproductive age in Lagos, Nigeria
}

\author{
Kabiru A Rabiu*, Adeniyi A Adewunmi, Fatimat M Akinlusi, Oluwarotimi I Akinola
}

\begin{abstract}
Background: Reproductive tract infections (RTI's) are endemic in developing countries and entail a heavy toll on women. If untreated, RTI's can lead to adverse health outcomes such as infertility, ectopic pregnancy and increased vulnerability to transmission of the human immunodeficiency virus. It is also associated with adverse pregnancy outcomes. While RTI's and its sequelae abound in Nigeria, there is paucity of publications on the subject in the country. This study assessed the understandings and care seeking behavior with regards to RTI's among women of reproductive age in Lagos, Nigeria with the aim of improving awareness on the subject.
\end{abstract}

Methods: A descriptive cross sectional survey of women attending the gynaecological outpatient and family planning clinics of the Lagos State University Teaching Hospital was carried out between $1^{\text {st }}$ June 2008 and $31^{\text {st }}$ August 2008 using a pre-tested questionnaire. Data was analysed using the Epi-Info 3.5 statistical software of the Centre for Disease Control and Prevention, Atlanta U.S.A.

Results: Most of the respondents (77.2\%) had heard of RTI's. Toilet was the most perceived mode of contracting RTI's (44.6\%), followed by sexual intercourse and poor hygiene. Vaginal discharge was the commonest symptom of RTI's named while inability to get pregnant was the commonest named complication. Majority of the respondent's demonstrated poor overall knowledge of symptoms and complications of RTI"s. 37.4\% of the respondents had experienced symptoms of RTI's in the preceding six months. Vaginal discharge was the commonest symptom reported (21.8\%) and the majority of those who reported symptoms sought medical treatment. Government health centres were the most visited health facilities for treatment.

Conclusion: Even though most of the respondents have heard of RTI's and sought treatment when symptomatic, they demonstrated poor overall understanding of the subject. There is need to educate women on preventive strategies, as RTI's are often assymptomatic.

\section{Background}

The global burden of reproductive tract infections (RTI's) is enormous and of a major public health concern, particularly in developing countries where RTIs are endemic [1].

RTI's, excluding Human Immunodeficiency Virus (HIV) constitute the second major cause of disease

\footnotetext{
* Correspondence: derabs@yahoo.co.uk

Department of Obstetrics and Gynaecology, Lagos State University Teaching Hospital, Ikeja, Lagos State, Nigeria
}

burden (after maternity related causes) in young adult women in developing countries [1].

RTI's cover three types of infections [2,3]: Sexually transmitted infections (STI's); infections that result from overgrowth of organisms normally present in the reproductive tract and infections associated with medical procedures including abortion and insertion of intra uterine devices. Female RTI's usually originate in the lower genital tract as vaginitis or cervicitis and may produce symptoms such as abnormal vaginal discharge, genital pain, itching and burning feeling with urination. 
However, a high prevalence of asymptomatic disease occur which is a barrier to effective control [4]. Even when symptoms occur, their presentation can overlap with and be diagnosed as a normal physiological change and normal physiological discharge may be misdiagnosed as RTI's [5].

Also the absence of approachable and comprehensive reproductive health services often means these symptoms must be tolerated stoically as an unfortunate but familiar reality of reproductive life [4].

In some instances, despite availability of these services, symptomatic persons do not seek or delay seeking appropriate diagnostic and treatment services [6].

RTI's entail a heavy toll on women; if untreated can cause serious consequences of infertility, ectopic pregnancy, cervical cancer, menstrual disturbances, pregnancy wastage and low birth weight babies [1]. The presence of RTI's especially ulcer causing STI's can enhance the acquisition and transmission of the human immunodeficiency virus [7].

Infertility is a major health problem in Africa, particularly in sub-Saharan Africa where $20-30 \%$ of couples are unable to conceive [8]. Most health advocates regard infertility as the most important reproductive health and social issue confronting Nigerian women and gynaecologists frequently report that infertility constitutes $60 \%$ $70 \%$ of their consultations in tertiary institutions [9]. In Nigeria, most cases of infertility follow RTI's [10].

Ectopic pregnancy constitutes a large percentage of acute gynaecological emergencies in Nigeria and is an important cause of maternal mortality [11-13]. A study in Lagos, Nigeria found previous STI's and pelvic inflammatory disease as major risk factors for ectopic gestation [14].

Cervical cancer is usually the result of sexually transmitted infection and human papilloma virus is the causative agent. It is the commonest reproductive tract malignancy and a leading cause of cancer death in Nigerian women [15]. In contrast to most other cancers, it is common below the age of 50 years and is therefore an important cause of premature death [16]. Other sequelae of RTI's also have enormous impact on the population [2,3].

Despite its enormous implications for women's health, the degree to which RTI's have been neglected by both the local and international health community is alarming. In allocating scare human and financial resources, most policy makers, programme planners and donor agencies consistently give low priority to control of these infections.

The current HIV/AIDS pandemic has undoubtedly done more havoc to shift attention from other RTI's. At this time of worldwide financial crisis, information on reproductive morbidities is essential in ensuring appropriate allocation of scarce resources and planning of cost effective health care strategies. To initiate any meaningful preventive measures for control of RTI's, there is need to create awareness and improve knowledge on the subject.

This study was carried out to assess the understandings and care seeking behavior with regards to RTI's among women of the reproductive age. Those patients attending the gynaecological and family planning outpatient clinics of the Lagos State University Teaching Hospital form a readily available and accessible group.

\section{Methods}

Design

The study was a descriptive cross sectional survey.

\section{Setting}

The study was conducted at the gynaecological out patient and family planning clinics of the Lagos state university teaching hospital (LASUTH), which is one of the two main referral hospitals with obstetrics and gynaecological services in metropolitan Lagos.

The gynaecological outpatient clinic takes place between 09.00 and 16.00 hours every working day of the week. The patients seen are referred from private hospitals, general hospitals within and outside Lagos as well as from other departments of LASUTH. An average of about 60 patients attend the clinics each day and about $20 \%$ of these are new patients

The family planning is open between 08.00 and 16.00 hours (Monday to Friday). Patients either walk into the clinic or are referred from the gynaecological or post natal clinics. An average of 20 patients attends the clinic each day.

\section{Study Population}

The participants in this study were the new patients who attended the gynaecological and family planning out-patient clinics of LASUTH between $1^{\text {st }}$ June and $31^{\text {st }}$ August, 2008. A total of 500 questionnaires were administered. Although the response rate was 100\%, 13 respondents were excluded because of observed inconsistencies in response to questions. Data was therefore complete in 487 respondents.

\section{Data Collection}

The instrument for data collection was a pre-tested questionnaire. The purpose of the study was explained to the patients and those who consented were interviewed by the authors, and medical students who had been carefully briefed about the technique of administration. Confidentiality was maintained by not including their names and addresses so as to elicit correct responses. 
The technique of face to face interview was used for data collection.

The questionnaire was in three parts;

The first part solicited for socio-demographic characteristics of the respondents; the second part assessed their understandings of RTI's, while the third part assessed care seeking behaviour. We specifically asked them if they knew whether any of the four commonly chosen contraceptive methods in our centre (Condoms, intrauterine contraceptive devices, oral contraceptive pills and implants) increase, decrease, or does not have any effect on the transmission of RTI's. All the questions were constructed in the same style and were either direct (single or multiple) or open ended.

\section{Analysis}

The open ended questions were first categorized and all the data obtained were entered into the computer and analysed using EPI - info 3.5 statistical software (2008 version) of the Centre for Disease Control and Prevention Atlanta, USA and presented in descriptive and tabular forms as frequencies and percentages.

\section{Ethics}

Formal approval for the study was obtained from the Research Ethics Committee of the Lagos State University Teaching Hospital. Participation of the patients was voluntary and only those who gave their consent after the purpose of the study had been explained to them participated in the study.

\section{Results}

A total of 500 new patients from the gynaecological and family planning out patients clinics of the Lagos State University Teaching Hospital who gave their consent participated in the study. Data were complete for analysis in 487(97.4\%) Table 1 summarises the socio-demographic characteristics of the respondents. The mean age was $32.0 \pm 7.4$ years, the age range was $17-49$ years, and respondents were majorly in the 30-39 age.

Of all respondents, $84.0 \%$ were married, $14.2 \%$ single, $1.0 \%$ separated and $0.8 \%$ were widowed. Most of the respondents (79.9\%) were Christians while $20.1 \%$ were Muslims.

Most of the respondents (64.5\%) had tertiary education while only $2.5 \%$ had no formal education. The majority of the respondents $(52.2 \%)$ were engaged in skilled occupation.

Three hundred and seventy six $(77.2 \%)$ of the respondents had heard of RTI's while 111 (22.8\%) of them had not heard of RTI's. Sources of information were: health professionals-127(33.8\%), friends and relatives-106 (28.2\%), print media-45(12\%), religious groups -42 (11.2\%), electronic media-32(8.5\%) and school-14(3.7\%).
Table 1 Socio-demographic characteristics of respondents

\begin{tabular}{|c|c|c|}
\hline Characteristics & Frequency & Percentage \\
\hline \multicolumn{3}{|l|}{ Age in years } \\
\hline $10-19$ & 13 & 2.7 \\
\hline $20-29$ & $181^{\prime}$ & 37.2 \\
\hline $30-39$ & 221 & 45.4 \\
\hline $40-49$ & 72 & 14.8 \\
\hline \multicolumn{3}{|l|}{ Religion } \\
\hline Christianity & 389 & 79.9 \\
\hline Islam & 98 & 20.1 \\
\hline \multicolumn{3}{|l|}{ Marital status } \\
\hline Married & 409 & 84.0 \\
\hline Single & 69 & 14.2 \\
\hline Widowed & 4 & 0.8 \\
\hline Separated & 5 & 1.0 \\
\hline \multicolumn{3}{|c|}{ Educational status } \\
\hline None & 12 & 2.5 \\
\hline Primary & 22 & 4.5 \\
\hline Secondary & 139 & 28.5 \\
\hline Tertiary & 314 & 64.5 \\
\hline \multicolumn{3}{|l|}{ Occupation } \\
\hline Non-skilled & 111 & 22.8 \\
\hline Semi-skilled & 122 & 25.1 \\
\hline Skilled & 213 & 52.2 \\
\hline
\end{tabular}

Table 2 shows the response of the participants to the modes of acquiring RTI's and knowledge of symptoms. Toilet was the most perceived mode of contracting RTI's (44.6\%), followed by sexual intercourse (44.1\%) and poor hygiene $(24.8 \%)$.

Gonorrhoea was the commonest RTI named (23.4\%) followed by syphilis (16.0\%) and candida (9.9\%).

Table 3 shows the knowledge of the symptoms and complications of RTI's. Of all respondents, 281 (57.7\%) chose vaginal discharge as a symptom of RTI's, 263 (54.0\%) chose vaginal itching and 158 (32.4\%) chose lower abdominal pain.

Majority of the respondents knew inability to get pregnant as a complication of RTI's, as indicated by $57.5 \%$ of them. Other complications were less known.

Overall knowledge of the respondents about the symptoms of RTI's was poor with only $17.7 \%$ having good knowledge and $56.0 \%$ demonstrating poor knowledge Overall knowledge of complications was even worse with only $7.0 \%$ having good knowledge and $70.8 \%$ having poor knowledge.

Table 4 shows that the understandings of the respondents about the effects of contraception on RTI's is poor. $50.5 \%$ did not know the effect of condom and 
Table 2 Response to modes of acquiring RTI's and names of RTI's

\begin{tabular}{lll}
\hline Characteristics & Frequency & Percentage \\
\hline Modes of acquiring RTI's & & \\
Sexual intercourse & 215 & 44.1 \\
Poor hygiene & 121 & 24.8 \\
Toilet & 217 & 44.6 \\
Unsafe abortion & 99 & 20.3 \\
Unsafe delivery & 84 & 17.2 \\
Genital tract procedures & 69 & 14.2 \\
& & \\
Names of RTI's & & \\
Syphylis & 78 & 16.0 \\
Gonorrhoea & 114 & 23.4 \\
HIV/AIDS & 36 & 7.4 \\
Staphylococcus & 41 & 8.4 \\
Candida & 48 & 9.9 \\
Hepatitis & 1 & 0.2 \\
Trichomonas & 7 & 1.4 \\
\hline
\end{tabular}

$2.5 \%$ wrongly believe that it increased the risk of contacting RTIs. Their understandings about the oral contraceptive pills, IUCD and implants with regards to RTI's were also poor.

One hundred and eighty two of the respondents (37.4\%) had experienced symptoms of RTI's in the preceding six months before the study.

The commonest symptom experienced was vaginal discharge which was reported by $106(21.8 \%)$ of the respondents. Other symptoms reported include: vulval itching (17.7\%), lower abdominal pain (15.0\%), pain with menstruation $(8.8 \%)$, pain during intercourse $(2.7 \%)$, genital sore (1.2\%) and genital/groin swelling (1.0\%).

Table 5 shows that most patients $(87.9 \%)$ sought medical care when they experienced symptoms of RTI's. Only $9.9 \%$ treated self while $2.2 \%$ ignored symptoms. Government health centres were the most visited health facility for treatment of RTI's.

15 of the 22 respondents $(68.2 \%)$ who did not seek medical care gave short duration of symptoms as the reason for their behaviour.

\section{Discussion}

Reproductive Tract Infections account for a major burden of disease globally especially in the developing countries where it is hyperendemic [1]. This is not unconnected with the underlining cultural, traditional and socio- economic factors found in these countries.

Most of the women in the study were in the 30-39 years age group, which constitutes a substantial part of the active reproductive age group and are thus prone to RTI's.

Most of the respondents (77.2\%) had heard about RTI's. This is comparable to a similar study conducted
Table 3 Knowledge of symptoms and complications of RTI's

\begin{tabular}{|c|c|c|}
\hline Characteristics & Frequency & Percentage \\
\hline \multicolumn{3}{|c|}{ Knowledge of symptoms } \\
\hline Vaginal discharge & 281 & 57.7 \\
\hline Vulval itching & 263 & 54.0 \\
\hline Lower abdominal pain & 158 & 32.4 \\
\hline Painful urination & 138 & 28.3 \\
\hline Genital sore & 109 & 22.4 \\
\hline Pain during menses & 101 & 20.7 \\
\hline Genital/groin swelling & 78 & 16.0 \\
\hline Painful intercourse & 75 & 15.4 \\
\hline \multicolumn{3}{|c|}{${ }^{*}$ Overall knowledge of symptoms } \\
\hline Poor & 273 & 56.0 \\
\hline Fair & 128 & 26.3 \\
\hline Good & 86 & 17.7 \\
\hline \multicolumn{3}{|c|}{ Knowledge of complications } \\
\hline Infertility & 280 & 57.5 \\
\hline Cervical cancer & 89 & 18.3 \\
\hline Heavy menses & 84 & 17.2 \\
\hline Ectopic pregnancy & 78 & 16.0 \\
\hline Chronic pelvic pain & 78 & 16.0 \\
\hline Miscarriage & 76 & 15.6 \\
\hline Still birth & 71 & 14.6 \\
\hline Congenital anomaly & 58 & 11.9 \\
\hline \multicolumn{3}{|c|}{${ }^{*}$ Overall knowledge of complications } \\
\hline Poor & 345 & 70.8 \\
\hline Fair & 108 & 22.2 \\
\hline Good & 34 & 7.0 \\
\hline
\end{tabular}

*A total of 8 effects were scored. Knowledge of 0-2 = poor, Knowledge of 3-4 = fair, Knowledge of 5 and above $=$ good.

in Kenya which showed that over $96 \%$ of respondents were aware of RTI's [17]. A study in rural Bangladesh however reported that only $12 \%$ of the study population had basic understanding of RTI's [18]. In rural west Bengal 57\% had knowledge of RTI's [19].

The great disparity in the proportion of the various populations who were aware of RTIs could be explained from the rural nature of West Bengal and Bangladesh where most of the respondents were illiterates, when compared to the urban settings of Nigeria and Kenya where the literacy level is higher.

In this study, more of the respondents (44.6\%) chose toilet as the mode of acquiring RTI's, thereby erroneously attributing more significance to toilet rather than sexual intercourse which was chosen in $44.1 \%$ of the respondents as a mode of contracting RTI's. Procedures in the genital tract including abortion were only perceived as a mode of acquiring RTI's in only a few of the respondents. This is in a population where induced 
Table 4 Understandings of the effects of contraception on transmission of RTI's

\begin{tabular}{lll}
\hline Type of contraception & Frequency & Percentage \\
\hline Condom & 12 & 2.5 \\
Increase & 196 & 40.2 \\
Decrease & 33 & 6.8 \\
No effect & 246 & 50.5 \\
I don't know & & \\
IUCD & 22 & \\
Increase & 31 & 4.5 \\
Decrease & 56 & 6.4 \\
No effect & 378 & 11.5 \\
I don't know & & 77.6 \\
& & \\
OCP & 11 & 2.3 \\
Increase & 32 & 6.6 \\
Decrease & 54 & 11.1 \\
No effect & 390 & 80.1 \\
I don't Know & & \\
Implants & & \\
Increase & 10 & 2.1 \\
Decrease & 13 & 2.7 \\
No effect & 53 & 10.9 \\
I don't know & 411 & \\
\hline
\end{tabular}

abortion is still a major public health problem accounting for about 20,000 deaths annually [20].

In Nigeria, abortion has not been legalised and as such abortions are performed under clandestine conditions where asepsis is not recognised. Most deaths from induced abortion are due to infection [21].

In a Karachi study no respondent mentioned sexual intercourse as a mode of contacting RTI's [22], whereas in Lima, Peru, knowledge of sexual contact as one way of transmitting RTIs was high [23].

This study shows that knowledge of the names of RTI's was poor as only $23.4 \%$ mentioned gonorrhoea as a cause of RTI's while $16.0 \%$ and $9.9 \%$ mentioned syphilis and candida respectively.

Vaginal discharge was the most perceived symptom of RTI's. This was not unexpected as previous reports from Nigeria have shown vaginal discharge as a common complaint in self referred cases to the gynaecological clinic $[24,25]$. It was also not surprising that pruritus vulvae was the second commonest perceived symptom of RTI's as Trichomonas vaginalis and Candida albicans which are common causes of vaginal discharge also cause pruritus.

It is worthy of note that genital sore was poorly perceived as a symptom and because of its association with increased incidence of HIV/AIDS, there is need to make
Table 5 Care seeking behaviour

\begin{tabular}{|c|c|c|}
\hline Characteristics & Frequency & Percentage \\
\hline \multicolumn{3}{|c|}{ Behaviour with symptoms $(\mathrm{n}=182)$} \\
\hline Ignored symptoms & 4 & 2.2 \\
\hline Treated self & 18 & 9.9 \\
\hline Sought medical care & 160 & 87.9 \\
\hline \multicolumn{3}{|c|}{ Care providers in those who sought Medical care $(n=160)$} \\
\hline Government Health Centre & 56 & 31.5 \\
\hline General Hospital & 23 & 12.9 \\
\hline Private Hospital & 34 & 19.1 \\
\hline Pharmacy & 40 & 22.5 \\
\hline Herbal home & 14 & 7.8 \\
\hline Nursing home & 11 & 6.2 \\
\hline \multicolumn{3}{|c|}{ Response to reasons for not seeking medical care $(n=22)$} \\
\hline Absence of perceived morbidity & 2 & 9.1 \\
\hline Mildness of symptoms & 5 & 22.7 \\
\hline Short duration of symptoms & 12 & 54.5 \\
\hline Financial reasons & 3 & 13.6 \\
\hline
\end{tabular}

the populace aware of the importance of the symptom as it relates to HIV transmission.

Inability to get pregnant topped the list of reported complications of RTI's. This is perhaps a reflection of the importance attached to childbearing in our society whereby any affectation of the genital region may be perceived as preventing pregnancy. Unfortunately, ectopic pregnancy with its enormous contribution to maternal morbidity and mortality in our country was poorly perceived as a complication of RTI's. The perceptions of other complications such as cancer of the cervix as related to RTIs were also poor.

The overall knowledge of symptoms and complications in this study were poor. There was poor knowledge of contraception and its role in preventing RTI's. This is however not surprising as the contraceptive prevalence in Nigeria is well below $10 \%$ [26]. The major obstacles to deriving benefits from contraception among our women include ambivalence towards modern contraception which is particularly grounded in the fear of side effects, poor quality services, and opposition from family members or influential members of the community [26].

Regarding prevalence of symptoms, $37.4 \%$ of respondents had experienced at least one symptom in the previous 6 months. This finding is similar to 41.3\% reported from Shimla City, Northern India [27], but much lower than that reported from a study in west Bengal, India, where $66.1 \%$ of women of reproductive age reported symptoms related to the reproductive tract [19].

Vaginal discharge was the commonest symptom experienced in this study in contrast to a study in rural 
Lebanon [28] where lower abdominal pain (41.1\%), vaginal itching (38.5\%) and painful coitus (40.7\%) were the leading symptoms experienced. Only $24.5 \%$ had experienced vaginal discharge.

In this study, the majority of the respondents (87.9\%) sought medical care. This may be due to the fact that infertility is known by many to result from RTI's and to prevent such dreaded complications women tend to seek medical care rather than face the consequences. It also indicates that intervention to reduce morbidity arising from RTIs should be directed mainly towards preventing RTI's rather than cure as most of the respondents will seek treatment when symptomatic.

Government Health Centre's were the main facilities where treatment was sought. This may be largely due to the fact that many health centre's are located in each local government area close to the people. Their services are also very cheap and sometimes free. In addition they are not as busy as the general hospitals which serve as a referral centre for more complicated cases and patients have to wait for long hours before being attended to.

This finding is different from what is reported in West Bengal where most respondents $(41.5 \%)$ patronized private doctors [19]. Perhaps the expensive nature of private hospitals in Lagos could explain this difference.

Another interesting consideration in the choice of care providers is the unrestricted access of the populace to medications, including antibiotics without prior medical consultation. Pharmaceuticals are obtained over the counter and often self administered on the basis of prior personal experience or lay advice from neighbours and family members. This results in a lot of patients patronizing pharmacies even more than they patronize the general hospitals or private doctors as shown in this study.

It is important to understand the limitations of our study. For prevalence of symptoms and care seeking behaviour of the participants, we relied upon self reported answers to events that may have occurred earlier and these may be subject to recall and reporting bias. Also, severe symptoms are likely to be remembered longer than mild symptoms.

\section{Conclusion}

The result of this study shows that even though most of the respondents had heard of RTI"s, they demonstrated poor understanding of the subject.

The prevalence of symptoms of RTI's in this study is high compared to that reported in other studies and most of those who reported symptoms sought medical care.

This implies that health intervention measures directed towards reducing morbidities from RTI's need not focus mainly on treatment of RTI's but rather on disease preventing strategies. These include educating women about ways of preventing RTI's such as the avoidance of high risk sexual behaviours and use of barrier contraceptive methods as reproductive tract infections are often assymptomatic.

RTI preventive programmes should be integrated into other reproductive health care programmes such as family planning, maternal and child health services with a view to providing a broad based reproductive health care.

\section{Acknowledgements}

The authors acknowledge the assistance of all members of staff of the medical record, gynaecology and family planning clinics of the Lagos State University Teaching Hospital. We also acknowledge the following medical students for their special role during the process of data collection: Nurat Logun, Mayowa Ayanda and Kehinde King.

\section{Authors' contributions}

KAR conceived the study and participated in its design and co-ordinated the training of interviewers, data collection, analysis and wrote the first draft of the paper. AAA participated in the study design, data collection, analysis and helped to draft the manuscript. FMA participated in the study design, data collection, analysis and helped to draft the manuscript. OIA participated in the study design, analysis and helped to draft the manuscript. All authors read and approved the final manuscript.

\section{Competing interests}

The authors declare that they have no competing interests.

Received: 12 November 2009 Accepted: 23 March 2010

Published: 23 March 2010

\section{References}

1. World Health Organisation: Global prevalence and incidence of selected curable sexually transmitted infections. Overview and Estimates Geneva: WHO 2001.

2. Wasserheit JN: The significance and scope of reproductive tract infections among third world women. Int J Gynaecol Obstet 1989, 30(S1):145-168.

3. Infection-free sex and protection. Reproductive health in developing countries: expanding dimensions and building solutions National Academy Press, Washington DCTsui AO, Wasserheit JN, Haaga JG 1997, 40-84.

4. Elias C: Reproductive tract infections: Global impact and priorities for women's reproductive health. Reproductive Health Matters Plenum Press, New York, 1992Adrienne Germain, King K Holmes, Peter Piot, Judith Wasserheit 1993, 1(1):111-112.

5. Trollope-Kumar K: Symptoms of reproductive tract infection-not all they seem to be. Lancet 1999, 354(9192):1745-1746.

6. Malta M, Bastos FI, Strathdee SA, Cunnigham SD, Pilotto JH, Kerrigan D: Knowledge, perceived stigma, and care seeking experiences for sexually transmitted infections: a qualitative study from the perspective of public clinic attendees in Rio de Janeiro, Brazil. BMC PublicHealth 2007, 7:18.

7. Fleming DT, Wasserheit JN: From epidemiological synergy to public health policy and practice: the contribution of other sexually transmitted diseases to sexual transmission of HIV infection. Sex Transm Infect 1999, 75(1):3-17.

8. Sciarrha J: Infertility: An International Health Problem. Int J Gynaecol Obstet 1994, 46(2):155-163.

9. Okonofua FE, Harris D, Odebiyi A, Kane T, Snow RC: The Social meaning of meaning of infertility in Southwest Nigeria. Health Transition Review Review 1997, 7(2):205-220.

10. Snow RC, Okonofua FE, Kane T, Farley TMM, Pinol A: Prevalence and determinants of infertility in Ile-Ife, Nigeria, Contracep Fert Sex. 1997, 23(1):544.

11. Ikeme ACC, Ezegwui HU: Morbidity and mortality following tubal ectopic pregnancies in Enugu, Nigeria. J Obstet Gynaecol 2005, 25(6):596-598. 
12. Igberase GO, Ebeigbe PN, Igbekoyi OF, Ajufoh BI: Ectopic pregnancy: an 11-year review in a tertiary centre in the Niger Delta. TropDoct 2005, 35(3):175-177.

13. Gharoro EP, Igbafe AA: Ectopic pregnancy revisited in Benin City, Nigeria: analysis of 152 cases. Acta Obstet Gynecol Scand 2002, 81(12):1139-1143.

14. Anorlu RI, Oluwole A, Abudu OO, Adebanjo S: Risk factors for ectopic pregnancy in Lagos, Nigeria. Acta Obstet Gynecol Scand 2005, 84(2):184-188.

15. Thomas JO: Cancer registration and diagnosis in Ibadan. Archives of Ibadan Medicine 2000, 1(2):5-6.

16. Dey MP, Woodman CBJ: Epidemiology and pathogenesis of cervical cancer. Gynaecologic oncology: Current diagnosis and treatment WB Saunders Company Ltd, LondonShingleton HM, Fowler WC, Jordan JA, Lawrence WD 1996, 1-8.

17. Wools KK, Menya D, Muli F, Heilman D, Jones R: Perception of risk, sexual behavior and STD/HIV prevalence in western Kenya. East Afr Med J 1998, 75(12):679-83.

18. Khan MA, Rahman M, Khanam PA, Barkat-e-Khuda, Kane TT, Ashraf A: Awareness of sexually transmitted disease among women and service providers in rural Bangladesh. Int J STD AIDS 1997, 8(11):688-96.

19. Dawn A, Biswas R: Reproductive tract infection: an experience in rural West Bengal. Indian J Public Health 2005, 49(2):102-3.

20. Raufu A: Unsafe abortion causes 20,000 deaths a year inNigeria. BMJ 2003, 326(7382):225.

21. Stubblefield PG, Grimes DA: Septic abortion. NEngl J Med 1994, 331(5):310-4.

22. Bhatti LI, Fikree FF: Health-seeking seeking behavior of Karachi women with reproductive tract infections. Soc Sci Med 2002, 54(1):105-17.

23. Hernandez LS, Winch PJ, Parker K, Gilman RH: Understandings of reproductive tract infections in a peri-urban pueblo joven in Lima Peru. BMC Womens Health 2006, 6:7.

24. Abudu OO, Anorlu Rl: Vaginal discharge. Text book of Obstetrics and Gynaecology for Medical Students Heineman Educational Books (Nigeria) PIcAgboola AA, Second 2005, 70-77.

25. Oladimeji AO, Ayuba TT, Adewole IF, Babarinsa IA, Bakare RA: Clinicopathologic Study of vaginal discharge in Ibadan. NigQt J Hosp Med 1998, 8(1):6-8.

26. d'Arcangues CM, Vogelsong KM: Recent advances in family planning methods. Archives of Ibadan Medicine 2002, 3(1):6-9.

27. Parashar A, Gupta BP, Bhardwaj Al, Sarin R: Prevalence of RTIs Among Women of Reproductive Age Group in Shimla City. IndianJournal Medicine 2006, 31(1):15-17.

28. Deeb ME, Awwad J, Yeretzian JS, Kaspar HG: Prevalence of reproductive tract infections, genital prolapse, and obesity in a rural community in Lebanon. Bull World Health Organ 2003, 81(9):639-649.

\section{Pre-publication history}

The pre-publication history for this paper can be accessed here: http://www. biomedcentral.com/1472-6874/10/8/prepub

doi:10.1186/1472-6874-10-8

Cite this article as: Rabiu et al:: Female reproductive tract infections: understandings and care seeking behaviour among women of reproductive age in Lagos, Nigeria. BMC Women's Health 2010 10:8.

\section{Submit your next manuscript to BioMed Central and take full advantage of:}

- Convenient online submission

- Thorough peer review

- No space constraints or color figure charges

- Immediate publication on acceptance

- Inclusion in PubMed, CAS, Scopus and Google Scholar

- Research which is freely available for redistribution 